\title{
Dextran Sulphate of Sodium-induced colitis in mice: antihyperalgesic effects of ethanolic extract of Citrus reticulata and potential damage to the central nervous system
}

\author{
ALEXANDRE S. HILEL ${ }^{1,2}$, BRUNA GYSEMANS ${ }^{2,3}$, MARIA E.M. LISBÔA ${ }^{2,3}$, ANA C. HEYMANNS ${ }^{1,2}$, \\ VIVIANE FREIBERGER ${ }^{1,2}$, LETÍCIA VENTURA ${ }^{1,2}$, RACHEL F. MAGNAGO ${ }^{4}$, CLARISSA M. COMIM ${ }^{1,2}$, \\ VERÔNICA HOREWICS ${ }^{1,2}$, DANIEL F. MARTINS ${ }^{1,2}$, FRANCIANE BOBINSKI ${ }^{1,2}$ and ANNA P. PIOVEZAN ${ }^{1,2}$ \\ 'Programa de Pós-Graduação em Ciências da Saúde, Universidade do Sul de Santa Catarina/ \\ UNISUL, Avenida Pedra Branca, 25, 88137-270 Palhoça, SC, Brazil \\ ${ }^{2}$ Laboratório de Neurociência Experimental/LaNex, Universidade do Sul de Santa Catarina/ \\ UNISUL, Avenida Pedra Branca, 25, 88137-270 Palhoça, SC, Brazil \\ ${ }^{3}$ Curso de Graduação em Medicina, Universidade do Sul de Santa Catarina/ \\ UNISUL, Avenida Pedra Branca, 25, 88137-270 Palhoça, SC, Brazil \\ ${ }^{4}$ Programa de Pós-Graduação em Ciências Ambientais/UNISUL, Avenida Pedra Branca, 25, 88137-270 Palhoça, SC, Brazil
}

Manuscript received on November 27, 2017; accepted for publication on March 26, 2018

\begin{abstract}
Citrus species are widely related to antihyperalgesic and anti-inflammatory effects. The aim of this study was to investigate if treatment with ethanolic extract from peels of mature Citrus reticulata Blanco causes antihyperalgesic effects on the referred mechanical hyperalgesia in a model of dextran sulphate of sodium (DSS)-induced colitis in mice, as well as the possible oxidative damage in different regions of the brain induced by its inflammatory reaction. Antihyperalgesia ( 30 to $300 \mathrm{mg} / \mathrm{kg}$ ) was investigated by behavioral response (frequency of response to von Frey filament stimulation) in Swiss mice, while damage to central nervous system was investigated through techniques that evaluated oxidative stress using male black C57 BL6 mice ( $\mathrm{n}=8)$. Treatment of the animals with the extract $(100 \mathrm{mg} / \mathrm{kg})$ from days 3 to 5 after colitis induction reduced referred the mechanical hyperalgesia $(32.6 \pm 5.1)$ in relation to the control group (57.4 \pm 2.0 ). Levels of lipid peroxidation or carbonyl proteins were augmented in colitis-induced animals in relation to the disease group. These results indicated an antihyperalgesic effect of the studied extract and a potential impairment of the central nervous system functioning caused by inflammation during colitis, which could be related to mental disorders observed in patients suffering of this pathology.
\end{abstract}

Key words: Citrus reticulate, medicinal plants, inflammation, oxidative stress, central nervous system.

\section{INTRODUCTION}

Pain is a common problem in patients with inflammatory bowel disease (IBD), such as ulcerative colitis and Chron's disease, decreasing

Correspondence to: Anna Paula Piovezan

E-mail: anna.piovezan@unisul.br patients' quality of life, and being a common reason for hospital readmissions (Zobeiri et al. 2017, Mudireddy et al. 2017). Abdominal pain associated with these functional gastrointestinal disorders may cause central sensitization, since a number of patients present extraintestinal painful symptoms, such as hyperalgesia in the upper limbs (Stabell 
et al. 2013). These symptoms are also associated with psychiatric disorders (IsHak et al. 2017).

This hypothesis is also related to the fact that mental disorders, such as sleep disturbances, depression, and anxiety are associated with these conditions, especially in patients with great severity of illness (Conley et al. 2017). A wellaccepted hypothesis for the appearance of mental symptoms during IBD is the impairment of brain structures, which can be triggered by the access of inflammatory mediators from periphery to the CNS, initially by crossing the blood-brain barrier (BBB) (Natah et al. 2005, Hathaway et al. 1999). If this is the case, different mechanisms could contribute to the pathogenesis of mental disorders, such as the dysfunction in the brain-gut axis and the increase of pro-inflammatory factors, such as reactive oxygen or nitrogen species, and cytokines (Nowakowsky et al. 2016). In the latter case, it is interesting to note that, in experimental studies, interleukin1beta (IL-1 $\beta$ ) has been recently implicated in the induction of depressive-like behaviors (Godbout et al. 2008) and cognitive impairment following experimental bacterial meningitis (Barichello et al. 2015), notably when centrally administered, and through the involvement of brainstem structures (Kurosawa et al. 2016).

All these data emphasize the need for a better understanding about neural processing of visceral pain in patients with inflammatory bowel diseases, as well as the phenomena by which intestinal inflammation can lead to CNS impairments, causing mental disorders, such as depression. Such knowledge would contribute to future development of more effective therapeutic strategies for those conditions, identifying plants as potential targets of interest in the development of anti-inflammatory molecules of medical interest.

Among those plants, Citrus reticulata has been studied in our laboratory and demonstrated important activity in pain and inflammation models of nociception. Citrus genus is one of the most important crops worldwide and Citrus reticulata peels are rich in phenolic compounds and flavonoids with high antioxidant properties (Safdar et al. 2017). In addition, the treatment of animals with naringenin alone, which is found in the peel of this plant, has demonstrated different effects in animal models of ulcerative colitis (Al-Rejaie et al. 2013, Azuma et al. 2013).

Taking this into account, the objective of the present study was to investigate the effects of the treatment with ethanolic extract from peels of mature Citrus reticulata Blanco (EECR) on the mechanical hyperalgesia in DSS-induced colitis mice, as well as the possible oxidative damage in different brain regions caused by intestinal inflammation induction.

\section{MATERIALS AND METHODS}

PRODUCTION OF THE ETHANOLIC EXTRACT FROM PEELS OF MATURE Citrus reticulata BLANCO (EECR)

Citrus reticulata fruits were obtained from a farm in the municipality of Araranguá, State of Santa Catarina, Brazil (latitude 28 $8^{\circ} 6^{\prime} 05^{\prime \prime}$ South and longitude: 49²9'09" West). They were identified by Professor Jasper Zanco, and a specimen voucher (SRS 00050047) was deposited in the Laelia purpurata herbarium of Universidade do Sul de Santa Catarina (UNISUL). For the preparation of the EECR, peels of the mature plant were removed and dried $\left(36^{\circ} \mathrm{C}\right)$, milled and standardized, using particles within the range of $250-850 \mathrm{~nm}$. The extract was produced at a ratio of $1: 8$ peels/ solvent-to-ethanol under dynamic maceration, and the fluid remained in contact with the peels for 10 days, under constant stirring in a closed vessel at room temperature. At the end, the EECR was concentrated using a rotary evaporator under reduced pressure to evaporate the solvent, in a water bath at a temperature ranging between $35^{\circ} \mathrm{C}$ and $40^{\circ} \mathrm{C}$ until complete evaporation of the ethanol. 


\section{ANIMALS}

Experiments were conducted using male black $\mathrm{C} 57$ BL6 (20-25 g) or Swiss (25-30 g) mice. They were maintained under standardized conditions of $12 \mathrm{~h}$ light-dark cycles and temperature $\left(22 \pm 2^{\circ} \mathrm{C}\right)$, with access to food and water ad libitum. Experiments were conducted from 8:00 a.m. to 5:00 p.m., after laboratory acclimatization. The experimental protocols were approved by the University Ethics Committee on Animal Use (15.010.4.03.IV and 16.026.5.01.IV). The number of animals ( $n=8$ per group) and noxious stimulus intensity rates were the minimum necessary to demonstrate the consistent effects of the drug treatments.

\section{DSS-INDUCED COLITIS}

Colitis induction was performed on Swiss mice groups to evaluate the EECR antihyperalgesic effect, whereas C57BL6 mice were used to evaluate the oxidative stress and determine IL-1 $\beta$ levels. The DSS group was composed of animals (weighting 25-30 g) fed ad libitum with a filtered water solution containing 3\% DSS, for of 5 days. The solution was replenished every 2 days. At day $6^{\text {th }}$ after colitis induction, the animals received just tap water to drink and were not treated with EECR. On this occasion, analyses were made to investigate a possible cumulative effect of the extract. Control mice (veh: vehicle group) received only tap water during the experiment.

In order to analyze possible anti-hyperalgesic effect of EECR, others groups of animals were orally pre-treated with vehicle (saline, $10 \mathrm{ml} / \mathrm{kg}$ ) or different doses of the extract (30 or $100 \mathrm{mg} / \mathrm{kg}$ ) and $1 \mathrm{~h}$ after they were evaluated to observe effects of the treatment on hyperalgesic response in relation to basal values. Doses of the extract were based on previous results of our group, demonstrating antihyperalgesic effect for hydroalcoholic extract of other plant in animal models of pain (De Mattos et al. 2007, Albano et al. 2013).
In order to analyze a possible antihyperalgesic effect of EECR, others groups of animals were orally pre-treated with vehicle (saline, $10 \mathrm{ml} / \mathrm{kg}$ ) or different doses of the extract (30 or $100 \mathrm{mg} / \mathrm{kg}$ ). They were evaluated $1 \mathrm{~h}$ after to examine the treatment effect on the hyperalgesic response in relation to base values. Doses of the extract were based on previous results of our group, demonstrating antihyperalgesic effect for hydroalcoholic extract of another plant in animal models for pain research (De Mattos et al. 2007, Albano et al. 2013).

\section{EVALUATION OF REFERRED MECHANICAL HYPERALGESIA}

Behavioral analyses for hind paws referred mechanical hyperalgesia conducted within a period of 6 days, using von Frey filaments $(0.6 \mathrm{~g})$. The animals were evaluated in individual plastic cages with a wire-mesh surface that was elevated $30 \mathrm{~cm}$ from the desk. Reactions elicited by 10 consecutive applications of stimulus were recorded according to previous work (Piovezan et al. 2017), as a response percent before (base) or at different times after starting DSS administration to animals (days 1 to 6). Positive responses were recorded when mice presented an abrupt withdrawal of the stimulated paw from the mesh. As mentioned above, the antihyperalgesic effect of EECR was evaluated at days 3 and 5 after colitis induction.

\section{EVALUATION OF POSSIBLE DAMAGE TO THE CNS DURING DSS-INDUCED COLITIS}

In the present study, the possible damage to CNS during intestinal inflammation induced by DSS was investigated by analyzing the parameters related to oxidative stress at the prefrontal cortex, hippocampus, striatum, and total cortex of the animals from the different treatment groups. For that purpose, determination of lipid peroxidation and protein carbonyl content in those tissues was performed as previous described by Albano et al. 2013. 
Besides that, possible alteration in the IL$1 \beta$ levels of the mice brainstem was investigated according to Barichello et al. 2015, with samples homogenized in phosphate-buffered saline (PBS), $0.1 \mathrm{mM}$ phenylmethylsulphonyl fluoride (PMSF), $10 \mathrm{mM}$ ethylenediaminetetraacetic acid (EDTA), $2 \mathrm{ng} / \mathrm{ml}$ Aprotinin, and $0.1 \mathrm{mM}$ benzemethonium chloridez. Sample aliquots of $100 \mu \mathrm{l}$ were used to measure the IL-1 $\beta$ levels, using ELISA kits (R\&D Systems), in an ELISA plate reader at $450 \mathrm{~nm}$. All results were expressed as $\mathrm{pg} / \mathrm{mg}$ protein.

\section{STATISTICAL ANALYSIS}

Data are presented as means \pm SEM of 8 mice. Statistical differences between groups were determined by one or two-way ANOVA, when appropriated, followed by Tukey or Bonferroni's test, respectively. Prism 6 software (GraphPad, San Diego, USA) was used for the analyses. P-values less than 0.05 were considered to be statistically significant.

\section{RESULTS}

\section{ANTIHYPERALGESIC EFFECT OF EECR}

At day 3 after induction of colitis with 3\% DSS, mice exhibited pronounced referred hyperalgesia to mechanical stimulation of the hind paw (vehicle group: $17.1 \pm 8.1$ arbitrary units; DSS-group: 56.7 \pm 9.5 arbitrary units) and the administration of DSS (Fig. 1). In the meanwhile, treatment with $100 \mathrm{mg} / \mathrm{kg}$ EECR, from day 3 up to day 5 after colitis induction, reduced mechanical hyperalgesia when animals were evaluated $1 \mathrm{~h}$ after receiving the extract. This effect can be better observed by the area under the curve from results obtained at day 6 after DSS-induced colitis (DSS group: 57.4 $\pm 8.2 \%$ frequency of response; EECR $100 \mathrm{mg} / \mathrm{kg}$ : $32.6 \pm 5.1 \%$ frequency of response). Furthermore, no residual antihyperalgesic effect from treatment was observed on day 6 at base.
EVALUATION OF POSSIBLE DAMAGE TO THE CENTRAL NERVOUS SYSTEM (CNS) DURING DSSINDUCED COLITIS

The results of biochemical analysis evaluating the different aspects of oxidative stress in CNS regions are presented in Table I. The analysis indicated there was augmentation in the levels of lipid peroxidation or carbonyl proteins in central nervous tissues at day 6 after DSS-induced colitis.

Biochemical analysis of mice brainstem revealed that DSS-induced colitis did not alter the IL-1 $\beta$ levels between the groups (Fig. 2). At day 6 after colitis induction, the scores in the DSS-group $(60.2 \pm 7.2 \% \mathrm{pg} / \mathrm{mg}$ of protein) were similar to those of the vehicle-group $(62.9 \pm 5.0 \% \mathrm{pg} / \mathrm{mg}$ of protein).

\section{DISCUSSION}

The present study demonstrated that EECR presents systemic antihyperalgesic activity during inflammatory DSS-induced colitis in mice. This report reinforces previous results for the antiinflammatory and analgesic properties obtained by other authors, as discussed below.

A review by Shen et al. (2012) revealed that nobiletin, a flavonoid present in the peels and plants of this genus is able to diminish several inflammatory parameters during osteoarthritis models in animals. In another review, Sakurada et al. (2009) have pointed out the importance of analgesic compounds present in the citrus genus, since intraplantar administration of essential oil from this plant promoted antinociceptive behavior in several pain models. In addition, Liang et al. (2017), have recently performed a meta-analysis to evaluate the efficacy of Chinese herbal medicine on post-herpetic neuralgia in humans. They found a beneficial effect for this therapy, including plants from citrus genus, such as Citrus aurantium L. and Citrus reticulata Blanco, the latter being the same as that used in the present study. 
TABLE I

Evaluation of possible damage to the CNS during DSS-induced colitis.

\begin{tabular}{cccc}
\hline CNS & Treatment & Lipid peroxidation & MDA \\
& & $\begin{array}{c}\text { Carbonyl proteins } \\
\text { DNPH }\end{array}$ & $\begin{array}{c}\text { (nmol/mg of protein) } \\
\text { (nmol } \mathbf{m g} \text { of protein) }\end{array}$ \\
\hline \multirow{2}{*}{ Prefrontal cortex } & Vehicle & $0.70 \pm 0.004$ & $83.0 \pm 6.20$ \\
& DSS & $0.99 \pm 0.009$ & $110.0 \pm 0.06^{(*)}$ \\
\hline \multirow{2}{*}{ Hippocampus } & Vehicle & $5.50 \pm 0.180$ & $42.0 \pm 12.00$ \\
\hline \multirow{2}{*}{ Striated } & DSS & $0.66 \pm 0.150$ & $67.0 \pm 6.50$ \\
& Vehicle & $0.79 \pm 0.140$ & $66.0 \pm 8.00$ \\
\hline \multirow{2}{*}{ Total cortex } & DSS & $1.20 \pm 0.009^{(*)}$ & $20.0 \pm 6.50$ \\
\hline
\end{tabular}

Vehicle, sterile saline (10 mL/Kg); CNS= central nervous system; DSS, Dextran Sulphate of Sodium 3\% in destiled water; MDA= malondialdehyde; DNPH=2,4-dinitrophenylhydrazine. Data presented as mean \pm S.E.M. (standard error of the mean, $n=8 /$ group). One-way ANOVA followed by Turkey test (P£0.05). Significant difference in relation to vehicle (*) group.

In this study, the antihyperalgesic activity of EBE-CR (Fig. 1) was approached in a way that had not yet been explored, during DSS-colitis models, which suggests a new possible therapeutic use for the plant. This is particularly important because the anti-inflammatory properties of nobiletin during osteoarthritis in animals, such as a decline of proinflammatory cytokines synthesis and reduction of pain and edema, are also common mechanisms involved in the pathogenesis of the ulcerative colitis (Nowakowsky et al. 2016). Furthermore, Azuma et al. (2013) have demonstrated that feeding animals with naringenin attenuated the disease activity and reduced colon shortening. In addition, it tended to suppress the increase in inflammatory cytokine expression, which would be consistent with a protective effect of the plant on intestinal barrier function.

Another important finding from the present study was related to the possible damage to the CNS caused by the inflammatory response of the bowel to oral DSS administration. In the present study, this procedure raised the oxidative stress parameters, such as carbonylated proteins and lipid peroxidation in central areas, such as prefrontal cortex, hypothalamus, striated, total cortex
(Table I), in similar extents to those observed by other authors using bacterial infection-induced inflammation models (Barichello et al. 2015). This finding may suggest a potential impairment of the CNS function that could be related to mental disorders observed in patients suffering from this pathology (Stabell et al. 2013, IsHak et al. 2017).

The damage observed in these areas could be formerly initiated by disruption of the blood-brain barrier(BBB), with inflammatory cells and mediators gaining access to the central nervous tissue. In this respect, Natah et al. (2005) have observed significant increases in the flow of sodium fluorescein through the BBB to the circumventricular regions, the organum vasculum of the terminal lamina, the subfornical organ, and the median eminence of the hypothalamus, 1 and 2 days after colitis induction by 2,4, 6-trinitrobenzene sulfonic acid solution (TBNS). In another study involving free radicals, Hathaway (2000) has demonstrated that BBB permeability was increased by $54 \%$ in TNBS-induced colitis in a rabbit animal model.

Depression is one of the most prominent mental disorders associated with colitis and inflammatory chronic conditions (Conley et al. 2017). Pre-clinical studies have recently implicated 


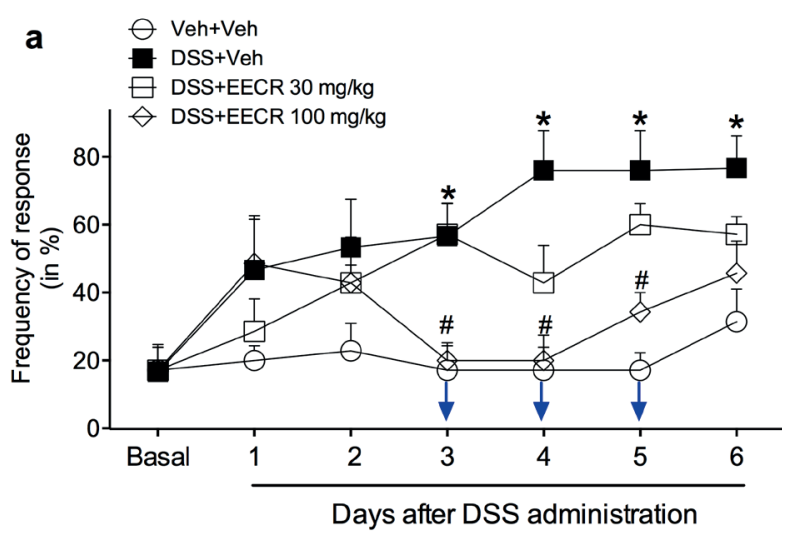

b

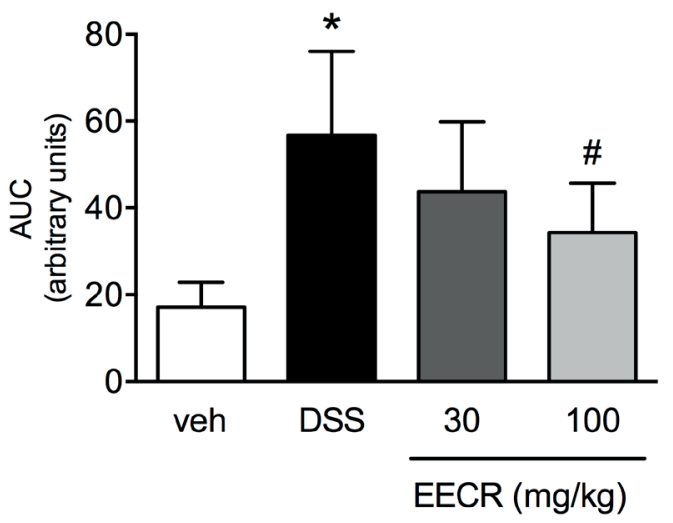

Figure 1 - Influence of EECR on DSS-induced colitis in mice. a: Referred mechanical hyperalgesia was measured as the reaction elicited by 10 consecutive applications of von Frey stimulus $(0.6 \mathrm{~g})$, with positive response recorded when mice presented a sharp withdrawal of the stimulated paw from the mesh. b: representative illustration for the area under the curve (AUC) for the different groups evaluated, arrows represent time-points for EECR treatment. Data are presented as mean \pm S.E.M, $\mathrm{n}=8$ animals. $\mathrm{P} \leq 0.05$ in relation to control group $\left(^{*}\right)$ or DSS group (\#), one or two-way ANOVA was undertaken followed by the Bonferroni test or Tukey, respectively.

IL-1 $\beta$, at brainstem structures, with the initiation of this condition (Godbout et al. 2008). In the present study, DSS administration did not alter IL-1beta levels in the brainstem of mice in relation to control groups (Fig. 2). It is possible that the procedure used in the present study, with colitis induced by DSS administration during a 5-day period was not strong enough to cause this change. However, it is important to mention that colitis is a chronic condition, and the measurement of this parameter should be addressed in future studies by evaluating

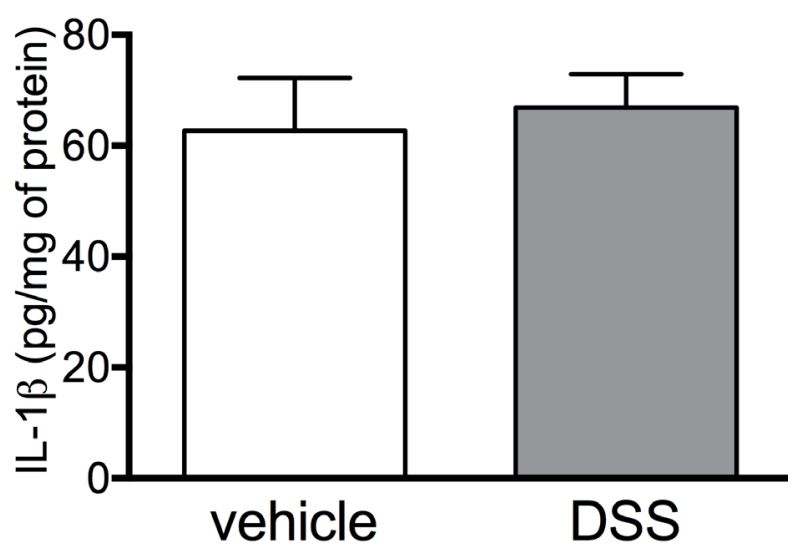

Figure 2 - Influence of DSS-induced colitis on IL-1 $\beta$ levels at brainstem of mice. Homogenized samples were employed for ELISA analysis using R\&D Systems kits and read at $450 \mathrm{~nm}$, thereafter. Data are presented as mean \pm S.E.M.

protocols for repeated cycles of DSS administration already used in the literature.

It is very well known that a high level of IL$1 \beta$ is expressed in the brain, particularly in the hippocampus, which plays a fundamental role in memory and mood regulation. Moreover, IL-1b exerts various effects in this area, such as neuronal proliferation, differentiation, apoptosis, and potentialization, which leads to its involvement in the pathogenesis of various psychiatric disorders and cognitive function in normal individuals (Tsai et al. 2017).

The current results demonstrate that systemic treatment of animals with ECCR presents important antihyperalgesic (analgesic) activity in DSSinduced colitis model in mice, suggesting that the plant constituents should be further investigated to examine their potential therapeutic effects on the inflammatory bowel disease. Furthermore, the central nervous system damage associated with intestinal inflammation in DSS-induced model should be further examined to understand better the pathogenesis of mental disorders during this condition.

\section{REFERENCES}

ALBANO MN, SILVEIRA MR, DANIELSKI LG, FLORENTINO D, PETRONILHO F AND PIOVEZAN AP. 2013. Anti-inflammatory and antioxidant properties of 
hydroalcoholic crude extract from Casearia sylvestris Sw. (Salicaceae). J Ethnopharmacol 147: 612-627.

AL-REJAIE SS, ABUOHASHISH HM, AL-ENAZI MM, ALASSAF AH, PARMAR MY AND AHAMED MM. 2013. Protective effect of naringenin on acetic acid-induced ulcerative colitis in rats. World J Gastroenterol 19: 56335644.

AZUMA T, SHIGESHIRO M, KODAMA M, TANABE S AND SUSUKI T. 2013. Supplemental naringenin prevents intestinal barrier defects and inflammation in colitic mice. J Nutr 143: 827-834.

BARICHELLO T, GENEROSO JS, SIMÕES LR, SHARIN VG, CERETTA RA, DOMINGUINI D, COMIM CM, VILELA MC, TEIXEIRA AL AND QUEVEDO J. 2015. Interleukin-1 $\beta$ Receptor Antagonism Prevents Cognitive Impairment Following Experimental Bacterial Meningitis. Curr Neurovasc Res 12: 253-261.

CONLEY S, PROCTOR DD, JEON S, SANDLER RS AND REDEKER NS. 2017. Symptom clusters in adults with inflammatory bowel disease. Res Nurs Health 40: 424434.

DE MATTOS ES, FREDERICO MJ, COLLE TD, DE PIERI DV, PETERS RR AND PIOVEZAN AP. 2007. Evaluation of antinociceptive activity of Casearia sylvestris and possible mechanism of action. J Ethnopharmacol 112: 1-6.

GODBOUT JP, MOREAU M, LESTAGE J, CHEN J, SPARKMAN NL, O'CONNOR J, CASTANON N, KELLEY KW, DANTZER R AND JOHNSON RW. 2008. Aging exacerbates depressive-like behavior in mice in response to activation of the peripheral innate immune system. Neuropsychopharmacology 33: 2341-2351.

HATHAWAY CA, APPLEYARD CB, PERCY WH AND WILLIAMS JL. 1999. Experimental colitis increases blood-brain barrier permeability in rabbits. Am J Physiol 276: G1174-1180.

HATHAWAY CA, PERCY WH AND WILLIAMS JL. 2000. Effects of free radicals and leukocytes on increases in blood-brain barrier permeability during colitis. Dig Dis Sci 45: 967-975.

ISHAK WW, PAN D, STEINER AJ, FELDMAN E, MANN A, MIROCHA J, DANOVITCHI I AND MELMED GY. 2017. Patient-Reported Outcomes of Quality of Life, Functioning, and GI/Psychiatric Symptom Severity in Patients with Inflammatory Bowel Disease (IBD). Inflamm Bowel Dis 23: 798-803.

KUROSAWA N, SHIMIZU K AND SEKI K. 2016. The development of depression-like behavior is consolidated by IL-6-induced activation of locus coeruleus neurons and IL-1 $\beta$-induced elevated leptin levels in mice. Psychopharmacology (Berl.) 233: 1725-1737.
LIANG H, COYLE ME, WANG K, ZHANG AL, GUO X, LI H, XUE CC AND LU C. 2017. Oral Chinese herbal medicine for post-herpetic neuralgia: a systematic review and meta-analysis of randomized controlled trials. Eur J Integr Med 10: 46-56.

MUDIREDDY P, SCOTT F, FEATHERS A AND LICHENSTEIN GR. 2017. Inflammatory Bowel Disease: Predictors and Causes of Early and Late Hospital Readmissions. Inflamm Bowel Dis 23: 1832-1839.

NATAH SS, MOUIHATE A, PITTMAN QJ AND SHARKEY KA. 2005. Disruption of the blood-brain barrier during TNBS colitis. Neurogastroenterol Motil 17: 433-446.

NOWAKOWSKY J, CHORBAK AA AND DUDEK D. 2016. Psychiatric illnesses in inflammatory bowel diseases psychiatric comorbidity and biological underpinnings. Psychiatr Pol 50: 1157-1166.

PIOVEZAN AP ET AL. 2017. Hydroalcoholic crude extract of Casearia sylvestris $\mathrm{Sw}$. reduces chronic post-ischemic pain by activation of pro-resolving pathways. J Ethnopharmacol 204: 179-188.

SAFDAR MN, KAUSAR T, JABBAR S, MUMTAZ A, AHAD K AND SADDOZAI AA. 2017. Extraction and quantification of polyphenols from kinnow (Citrus reticulate $\mathrm{L}$.) peel using ultrasound and maceration techniques. J Food Drug Anal 25: 488-500.

SAKURADA T, KUWAHATA H, KATSUYAMA S, KOMATSU T, MORRONE LA, CORASANTI MT, BAGETTA G AND SAKURADA S. 2009. Intraplantar injection of bergamot essential oil into the mouse hindpaw: effects on capsaicin-induced nociceptive behaviors. Int Rev Neurobiol 85: 237-248.

SHEN CL, SMITH BJ, LO DF, CHYU MC, DUNN DM, CHEN CH AND KWUN IS. 2012. Dietary polyphenols and mechanisms of osteoarthritis. J Nutr Biochem 23: 1367-1377.

STABELL N, STUBHAUG A, FLAEGSTAD T AND NIELSEN CS. 2013. Increased pain sensitivity among adults reporting irritable bowel syndrome symptoms in a large population-based study. Pain 154: 385-392.

TSAI SJ. 2017. Effects of interleukin-1beta polymorphisms on brain function and behavior in healthy and psychiatric disease conditions. Cytokine Growth Factor Rev 37: 8997.

ZOBEIRI M, BASHIRI H, ASKARI L, KESHAVARS AA, TAVVAFZADEH R, FATAHI K AND NAJAFI F. 2017. Epidemiologic Characteristics of Patients with Inflammatory Bowel Disease in Kermanshah, Iran. Middle East J Dig Dis 9: 164-169. 